\title{
3 Research Square

\section{Ureteroscopic lithotripsy combined with stent placement contributed to long-term auto-release of lithangiuria in upper urinary tract after ureterolithotripsy}

\section{Liujing Sun}

the No. Three People's Hospital of Changzhou

Jun Zhao ( $\nabla$ zj_topdog@163.com )

Changzhou Second People's Hospital Affiliated to Nanjing Medical University

Research article

Keywords: lithangiuria, ureteroscope, stent replacement, extracorporeal shock-wave lithotripsy

Posted Date: June 25th, 2020

DOl: https://doi.org/10.21203/rs.3.rs-37323/v1

License: (c) (1) This work is licensed under a Creative Commons Attribution 4.0 International License.

Read Full License 


\section{Abstract \\ Background}

To investigate the clinical efficiency of ureterectasis combined with stent placement in the long-term autorelease of lithangiuria in upper urinary tract after ureterolithotripsy.

\section{Methods}

In this retrospective analysis, we included the patients (male: 314; female: 49; age: 32-78 yrs; median age: $53 \mathrm{yrs}$ ) admitted to our hospital between January 2014 and January 2018 underwent ureterolithotripsy (URS group, $n=178$ ) and extracorporeal shock wave lithotripsy (ESWL group, $n=212$ ) for treating lithangiuria in upper urinary tract. All the patients were followed up for 24-59 months after treatment (median: 38 months). Uni-variate and multi-variate Logistic regression analysis was used to analyze the factors that could affect the long-term release of lithangiuria in upper urinary tract. Then we compared the short diameter of the ureter surpassing the stenosis of iliac vessels and the long-term autorelease of lithotripsy between the two groups.

\section{Results}

Logistic regression analysis indicated that the risk of auto-release of the stones in the upper urinary tract in the URS group was significantly higher than that of the ESWL group (OR =3.357, 95\% Cl: 1.234-9.137). Stent placement was an independent risk factor for long-term auto-release of lithotripsy $(P<0.01)$. The short diameter of the ureter surpassing the stenosis of iliac vessels after URS was significantly longer than that of the baseline level $(6.06 \pm 1.26 \mathrm{~mm}$ vs. $3.63 \pm 0.98 \mathrm{~mm}, \mathrm{t}=20.88, \mathrm{P}<0.01)$. The short diameter of the ureter surpassing the stenosis of iliac vessels after ESWL showed no statistical differences compared with that of the baseline level $(3.67 \pm 1.02 \mathrm{~mm}$ vs. $3.61 \pm 0.94 \mathrm{~mm}, \mathrm{t}=-0.798, \mathrm{P}=0.425)$. Sixteen cases $(2.8 \%)$ in the URS group showed auto-release of stones during the follow-up, which was significantly higher than that in the ESWL group with 6 cases (13.5\%) presented auto-release of stones $\left(X^{2}=6.895, P=0.09\right)$.

\section{Conclusions}

The combination of URS and stent replacement induced obvious ureterctasis, which may contribute to the auto-release of stones in the upper urinary tract in the long-term.

\section{Background}

Urolithiasis, a common condition in urinary tract, shows an increase in the prevalence with the aging process and the advances of imaging techniques [1-3]. In the majority of Asian countries, the prevalence 
of urolithiasis is increasing $[4,5]$. About $85 \%-93 \%$ of the urolithiasis is present in the upper urinary tract, including lithangiuria and ureteral calculus. In some cases, it may present concurrent with the renal colic, hydronephrosis, and fever, which may affect the health condition and life quality of the patients.

Extracorporeal shock wave lithotripsy (ESWL) and ureteroscopic lithotripsy (USR) have been well acknowledged as the two major methods for treating ureteric stones [6]. Among these two methods, ESWL has been considered to be mini-invasive as it induces less adverse events and complications. Besides, it involves lower expenditure for the patients. The treatment efficiency of URS is not affected by size and number of stone, as well as the position. To date, there are still some disputes on the selection of treatment regimen for these patients. In the clinical guideline, the regimen selection is usually based on stone feature, clinical signs, anatomical structure, medical techniques, as well as the expenditure [7].

Stent replacement after URS prompts release of urolithiasis and recovery of renal function. In the longterm follow-up, partial patients were reported to show simultaneous release of stones. In contrast, rare cases showed release of stones after ESWL, which may be related to the ureterectasis after stent replacement. This is mainly associated with the fact that ESWL or USR may lead to possibility of recurrence and necessity of treatment due to presence of residual fragments [8]. Therefore, the simultaneous release of stones mediated by ureterectasis after post-URS stent replacement may contribute to the long-term prevention of the upper urinary tract urolithiasis especially those with recurrence $[9,10]$. Besides, it may serve as a referring factor for the selection of URS treatment. Despite the conclusion is confirm, few reports have been focused on this aspect. On this basis, we retrospectively analyzed the clinical data of cases underwent ESWL or URS for treating upper urinary tract urolithiasis. Besides, we aimed to investigate the factors associated with the simultaneous release of stones after URS combined with stent replacement.

\section{Materials And Methods}

Clinical data

A total of 390 cases (male: 341; female: 49; age: 32-78 yrs; median: 52 yrs) admitted to our hospital between January 2014 and January 2018 underwent URS or ESWL for treating upper urinary tract urolithiasis were included in this study. The patients were divided into URS group $(n=178)$ and ESWL group $(n=212)$. According to the simultaneous release of the stones, the patients were divided into simultaneous release group $(n=22)$ and non-simultaneous release group $(n=368)$. The inclusion criteria were as follows: those received no URS or ESWL before admission; those were considered stone-free (SF) after treatment, or clinically insignificant residual fragments (CIRF); or those received no URS or ESWL in the follow-up $[11,12]$.

Observational indices and follow-up

The general and suspicious clinical risk factors were collected. Those with a body mass index (BMI) of > $24 \mathrm{~kg} / \mathrm{m}^{2}$ was considered to be obesity. All the patients received ultrasonography or computed 
tomography (CT) scan before and after treatment. SF was defined as absence or non-available of stones after ultrasonography or CT scan. The stone free rate (SFR) within 1 month was calculated after treatment. CIFR was defined as a diameter of stone of less than $4 \mathrm{~mm}$, and absence of clinical signs. Ultrasonic positioning was performed together with determination of the diameter in the stenosis upon ureter passing through the ilium at the following time points, including baseline, 1-3 months after ESWL, as well as 1-3 months after removal of stent in the URS group. The simultaneous release of the stones in the follow-up period was compared between the two groups.

\section{Methods}

For the ESWL, the patient was required to lie in supine position during the surgery. The lithotripsy was performed using the $108 \mathrm{G}$ stone-breaker (Zhanjiang, China). The voltage was set in a range of 11-12 kV. The impact frequency was in a range of 1,800-2,500. The decision of repeated lithotripsy was made according to the stone release 5-7 days afterwards. The frequency of lithotripsy should not be more than 3 times in the same body side.

For the URS, the patient lay in a lithotomy position. Paraffin oil was infused into the urinary tract, followed by gradual insertion of the ureteroscope (Wolf) into the bladder. The guide wire was inserted upon identifying the ureter orifice. Then the ureter wall space was dilated, followed by spiral insertion of the ureteroscope. The ureteroscope was inserted upwards in the guidance of the guide wire. The laser optical fiber was inserted to crush the stones, and then the stent tube was placed until removal about 1 month later.

The patients were followed up about 1 month after treatment. Follow-up was conducted through telephone or visiting the clinics. The follow-up duration lasted for 24 months to 59 months (median, 38 months).

\section{Statistical analysis}

Medcalc software was utilized for the statistical analysis. Measurement data were presented as mean \pm standard deviation. Inter-group comparison was performed using the independent t-test, Satterthwaite ttest or Mann-Whitney non-parametric test. The rate of sample between the groups was compared with the Chi square test or Fisher exact test. Uni-variate or multi-variate Logistic regression analysis was performed to evaluate the risk factors correlated with the long-term simultaneous release of stones from the upper urinary tract after treatment. $P$ value of less than 0.05 was considered to be statistically significant.

\section{Results}

Comparison of clinical features and simultaneous release of stones in the long-term follow-up 
Table 1 summarized the clinical symptoms of the URS group and ESWL group, respectively. The 1-month SFR in the URS group was significantly higher than that of ESWL group $(88.2 \%$ vs. $75.9 \%, P=0.002)$. The simultaneous release rate in the URS group was significantly lower than that of the ESWL group $(2.8 \%$ vs. $13.5 \%, \mathrm{P}<0.01)$. 
Table 1

Comparison of clinical characteristics in URS group and ESWL group

\begin{tabular}{|c|c|c|c|c|}
\hline Variables & $\begin{array}{l}\text { USR group }(n= \\
178)\end{array}$ & $\begin{array}{l}\text { ESWL group }(n= \\
212)\end{array}$ & $t / x^{2}$ & $\begin{array}{l}P \\
\text { value }\end{array}$ \\
\hline Age & $51.23 \pm 11.32$ & $52.95 \pm 12.47$ & 1.413 & 0.159 \\
\hline Gender & & & 0.177 & 0.674 \\
\hline Male & $153(85.9)$ & $179(84.4)$ & & \\
\hline Female & $25(14.1)$ & $33(15.6)$ & & \\
\hline Follow-up duration & $40.30 \pm 9.48$ & $41.76 \pm 12.57$ & -1.272 & 0.204 \\
\hline Stone features & & & 1.128 & 0.288 \\
\hline Single & $157(22.7)$ & $175(33.7)$ & 2.444 & 0.118 \\
\hline Multiple & $21(77.3)$ & $37(66.3)$ & & \\
\hline Stone position & & & 2.564 & 0.277 \\
\hline Left & $83(22.7)$ & $102(33.7)$ & & \\
\hline Right & $70(77.3)$ & $91(66.3)$ & & \\
\hline Bilateral & $25(77.3)$ & $19(66.3)$ & & \\
\hline $\begin{array}{l}\text { Ureteral stenosis, pre-treatment } \\
(\mathrm{mm})\end{array}$ & $3.63 \pm 0.91$ & $3.68 \pm 1.01$ & -0.508 & 0.612 \\
\hline $\begin{array}{l}\text { Ureteral stenosis, post-treatment } \\
(\mathrm{mm})\end{array}$ & $6.06 \pm 1.29$ & $3.65 \pm 0.99$ & -21.06 & 0.01 \\
\hline Obesity & & & 0.164 & 0.685 \\
\hline Yes & $57(32.0)$ & $72(33.9)$ & & \\
\hline No & $121(68.0)$ & $140(66.1)$ & & \\
\hline Hyperuricemia & & & 1.001 & 0.317 \\
\hline Yes & $48(26.9)$ & $67(31.6)$ & & \\
\hline No & $130(73.1)$ & $145(68.4)$ & & \\
\hline Hydronephrosis & & & 0.009 & 0.924 \\
\hline Yes & $126(70.8)$ & $151(71.2)$ & & \\
\hline No & $52(29.2)$ & $61(28.8)$ & & \\
\hline Diabetes & & & 0.001 & 0.993 \\
\hline Yes & $16(8.9)$ & $19(9.0)$ & & \\
\hline
\end{tabular}




\begin{tabular}{|lllll|}
\hline Variables & $\begin{array}{l}\text { USR group }(n= \\
\text { 178) }\end{array}$ & $\begin{array}{l}\text { ESWL group }(n= \\
\text { 212) }\end{array}$ & $t / \chi^{2}$ & $\begin{array}{l}P \\
\text { value }\end{array}$ \\
\hline No & $162(91.1)$ & $193(91.0)$ & & \\
\hline Hypertension & & & 1.836 & 0.175 \\
\hline Yes & $23(12.9)$ & $38(17.9)$ & & \\
\hline No & $155(87.1)$ & $174(82.1)$ & & \\
\hline
\end{tabular}

Risk factors associated with the simultaneous release of stones

Uni-variate and multi-variate Logistic regression analysis that there were no statistical differences in the age, gender, obesity, concurrent hyperuricemia, or hydronephrosis, diabetes mellitus and hypertension between the simultaneous release group and non-simultaneous release group $(P>0.05$, Table 2$)$.

Compared with the ESWL group, significant elevation was noticed in the risk of simultaneous release of stones in the URS group ( $\mathrm{OR}=3.357,95 \% \mathrm{Cl}$ : $1.234-9.137)$. Moreover, stent replacement was considered an independent risk factor for the simultaneous release of stones among the patients with upper urinary tract urolithiasis (Table 3). 
Table 2

Comparison of clinical characteristics in the patients with or without auto-release of stones

\begin{tabular}{|c|c|c|c|c|}
\hline Variables & $\begin{array}{l}\text { Auto-release group }(n= \\
22)\end{array}$ & $\begin{array}{l}\text { Non-auto-release group }(n= \\
368)\end{array}$ & $t / \chi^{2}$ & $\begin{array}{l}P \\
\text { value }\end{array}$ \\
\hline Age & $50.36 \pm 11.28$ & $52.27 \pm 12.02$ & 0.726 & 0.469 \\
\hline Gender & & & 1.136 & 0.286 \\
\hline Male & $17(77.3)$ & $315(85.6)$ & & \\
\hline Female & $5(22.7)$ & $53(14.4)$ & & \\
\hline $\begin{array}{l}\text { Stent } \\
\text { replacement }\end{array}$ & & & 6.895 & 0.009 \\
\hline Yes, URS & $16(72.7)$ & $162(44.0)$ & & \\
\hline No, ESWL & $6(27.3)$ & $206(56.0)$ & & \\
\hline Obesity & & & 1.128 & 0.288 \\
\hline Yes & $5(22.7)$ & $124(33.7)$ & & \\
\hline No & 17 (77.3) & $244(66.3)$ & & \\
\hline Hyperuricemia & & & 0.530 & 0.467 \\
\hline Yes & $8(36.4)$ & 107 (29.1) & & \\
\hline No & $14(63.6)$ & 261 (70.9) & & \\
\hline Hydronephrosis & & & & 0.674 \\
\hline Yes & $15(68.1)$ & 262 (71.2) & 0.092 & 0.810 \\
\hline No & 7 (31.9) & $106(28.8)$ & & \\
\hline Diabetes & & & - & 0.674 \\
\hline Yes & $3(13.6)$ & $32(8.7)$ & & \\
\hline No & $19(86.4)$ & $336(91.3)$ & & \\
\hline Hypertension & & & - & 0.778 \\
\hline Yes & $3(13.6)$ & $58(15.8)$ & & \\
\hline No & $19(86.4)$ & $310(84.2)$ & & \\
\hline -, Fisher exact me & & & & \\
\hline
\end{tabular}


Table 3

Risk factors associated with the auto-release of stones

\begin{tabular}{|lllll|}
\hline Variables & \multicolumn{2}{l}{ Univariate regression analysis } & \multicolumn{2}{l|}{ Multivariate regression analysis } \\
\cline { 2 - 5 } & OR $(95 \% \mathrm{Cl})$ & $\mathrm{P}$ value & OR $(95 \% \mathrm{Cl})$ & P value \\
\hline Age & $0.987(0.951-1.023)$ & 0.468 & $0.989(0.951-1.029)$ & 0.583 \\
\hline Gender & $1.748(0.619-4.939)$ & 0.292 & $1.880(0.619-5.712)$ & 0.265 \\
\hline Stent replacement & $3.391(1.298-8.861)$ & 0.013 & $3.357(1.234-9.137)$ & 0.018 \\
\hline Obesity & $0.311(0.090-1.070)$ & 0.064 & $0.368(0.099-1.373)$ & 0.123 \\
\hline Hyperuricemia & $0.658(0.352-2.239)$ & 0.480 & $0.980(0.314-2.048)$ & 0.495 \\
\hline Hydronephrosis & $1.348(0.819-3.939)$ & 0.361 & $1.880(0.810-4.512)$ & 0.378 \\
\hline Diabetes & $0.708(0.2-2.506)$ & 0.592 & $0.697(0.144-3.367)$ & 0.654 \\
\hline Hypertension & $0.844(0.242-2.944)$ & 0.790 & $0.980(0.224-4.282)$ & 0.979 \\
\hline
\end{tabular}

Comparison of iliac stenosis dimension:

The stenosis diameter in the ureter passing through the iliac vessels in the URS group showed significant decline after treatment compared with the baseline level $(3.63 \pm 0.98$ vs. $6.06 \pm 1.26 \mathrm{~mm}, t=20.88, P<$ $0.01)$. The stenosis diameter of ureter passing through the iliac vessels in the URS group showed no differences after treatment compared with the baseline level $(3.67 \pm 0.99 \mathrm{~mm}$ vs. $3.65 \pm 0.99 \mathrm{~mm}, \mathrm{t}=-0.34$, $P=0.734)$ (Fig. 1).

\section{Discussion}

The incidence of lithangiuria shows an increasing trend, especially the upper urinary tract urolithiasis. In contrast, the incidence of lower urinary tract urolithiasis, especially the bladder calculi, is on a sharp decline [13]. In a recent survey, the prevalence of renal calculus was up to $6.4 \%$ in China mainland [14]. To our best knowledge, upper urinary tract urolithiasis has been considered the most common urological diseases, which causes great burden to the public health. To date, ESWL and URS have been frequently utilized for treating upper urinary tract urolithiasis, leading to a SFR of $73 \%-91 \%$ and $93 \%-98 \%$, respectively [15]. Patients in the ESWL group achieved a $92.70 \%$ overall SFR with a $44.88 \%$ retreatment rate and an $11.02 \%$ auxiliary procedure rate [8]. In this study, the 1-month SFR in the ESWL group and URS group was $75.9 \%$ and $88.2 \%$, which was in line with the previous findings [16]. The residual calculi would serve as the infection source, which led to recurrence of calculi [9]. Moreover, the upper urinary tract urolithiasis was triggered by metabolic disorder induced by pathological factors and the potential interaction. After treatment, there would be newly generated calculi in the patients in a SF status. Multiple studies indicated that the 1-year and 3-5 year recurrence rate of urological calculi was $6.7 \%$ and $21.3 \%$ for the lithangiuria, respectively. The risk of lifelong recurrence was up to $60 \%-80 \%$. In a previous study, 
Vaughan et al [17] indicated that the stone recurrence rate was 3.4\% after the first episode, $7.1 \%$ after the second episode, $12.1 \%$ after the third episode, and $17.6 \%$ after the fourth or higher episode. Therefore, despite the fact that the standard for the outcome evaluation of residual fragments in the upper urinary tract was relied on the no residual stones after treatment [11, 12], some patients may present posttreatment recurrence, which showed increase in time with the disease duration and treatment frequencies [10]. On this basis, long-term prevention and treatment is necessary for these patients.

To date, the regimens based on drugs and nutrition interference for the simultaneous release of stones from the upper urinary tract have been considered the most safe and economic ways [7]. However, the stone release method based on drugs is not recommended for the long-term usage as many patients show poor treatment compliance [18]. The metabolic disorder induced stone formation was associated with intermittent rather than persistent factors that may affect the efficiency of nutrition and diet interference. Meanwhile, the metabolic disorder induced by stone formation showed an intermittent pattern [19]. Furthermore, the simultaneous release possibility of ureteral stones with a diameter of about 2-4 mm was up to $95 \%$, while that of the stones with a diameter of $>5 \mathrm{~mm}$ was merely $50 \%$. Therefore, conventional treatment regimen was not effective for the long-term prevention and management of upper urinary tract urolithiasis.

Post-URS stent replacement could prevent ureteric stenosis and obstruction, which could contribute to the recovery of renal function. In the long-term follow-up, the patients presented simultaneous release of stones after stent removal. In this study, the simultaneous release of stones in the URS group was significantly higher than that of the ESWL group. In addition, Logistic regression analysis indicated that stent replacement was an independent risk factor for the simultaneous release of the stones. The risk of auto-release of stones in the URS group showed increase, which were about 3-fold higher than that of the ESWL group. Further analysis indicated that the mean diameter of the stenosis in the ureter passing through the iliac vessels after treatment was up to $6 \mathrm{~mm}$, which showed an increase of $70 \%-100 \%$ compared with before. In the ESWL group, there were no significant differences. In a previous study [21], about $68 \%$ of the urological stones showed a diameter of less than $5 \mathrm{~mm}$. Therefore, dilation of ureter after stent removal contributed to the release of the majority of stones in the upper urinary tract. The treatment efficiency was more effective and convenient compared with the drugs or diet interference based regimens. Meanwhile, the efficiency was not hampered by the patient compliance and metabolic factors mediated by stone formation, which was beneficial to the treatment and long-term prevention of the upper urinary tract urolithiasis. The major features were as follows: (i) It could promote the autorelease of the residual CIRF stones, and attenuate the possibility of recurrence. (ii) There was no obstruction in the urinary tract after ureterectasis, together with decline of crystal deposition and stone recurrence in the urinary tract. (iii) It could correct partial congenital stricture of ureter, and induce decline of the recurrence of the stones. Moreover, based on the calculation of the ureter pressure [21], the pressure would be decline after ureterectasis, which may be beneficial to the recovery of renal function.

There are some limitations in this study. First, we do not measure the diameter of the ureter in the patients underwent CT scan. Compared with the ultrasonography, CT scan is more accurate and available. 
Second, the ureteric stenosis near the iliac vessels served as the evaluation standard, however, the pyeloureteral junction stenosis and bladder orifice stenosis were not evaluated. For the reasons, the pyeloureteral junction stenosis showed significant retraction due to severe pyelectasis and treatmentrelated factors, which could not accurately reflect the changes of the ureter diameter. The bladder orifice stenosis was near or embedded in the bladder, which could not be clearly displayed by ultrasonography or CT scan. Meanwhile, it passed through the iliac vascular stenosis and was localized in the middle of the ureter, which was convenient for the localization and evaluation as it was slightly affected by the pyelectasis.

Currently, the selection of URS or ESWL for treating upper urinary tract stones is mainly relied on the stone size and position [21], post-treatment SFR [23], and the complications. The combination of URS and stent replacement contributed to the ureterectasis and the simultaneous release of stones from the upper urinary tract. The method is easy to perform, and was not affected by the life habits and the internal environments. Therefore, it could be used as an evaluation standard for the URS, especially in the patients with obesity and hyperuricemia presenting high risks of recurrence as well as those with repeated recurrence.

\section{Abbreviations}

ESW: extracorporeal shock wave lithotripsy; USR:ureteroscopic lithotripsy; SF:stone-free; CIRF:clinically insignificant residual fragments; BMI:body mass index; CT:computed tomography; SFR:stone free rate

\section{Declarations}

\section{Ethics approval and consent to participate}

The study protocols were approved by the Ethical Committee of Changzhou Second People's Hospital Affiliated to Nanjing Medical University.

\section{Consent for publication}

Written informed consent was obtained from the participants for publication of this article and any accompanying tables/images. A copy of the written consent is available for review by the Editor of this journal.

\section{Availability of data and material}

The datasets used and/or analysed during the current study are available from the corresponding author on reasonable request.

\section{Competing interests}

The authors declare that they have no competing interests. 


\section{Funding}

Not applicable

\section{Authors' contributions}

SLJ wrote the manuscript; ZJ revised the manuscript; SLJ did the data analysis; ZJ did the data collection.

\section{Acknowledgements}

Not applicable

\section{References}

1. Sorokin I, Mamoulakis C, Miyazawa K, Rodgers A, Talati J, Lotan Y. Epidemiology of stone disease across the world. World J Urol. 2017;35:1301-20.

2. Yasui T, Iguchi M, Suzuki S, Okada A, Itoh Y, Tozawa K, et al. Prevalence and epidemiologic characteristics of lower urinary tract stones in Japan. Urology. 2008;72:1001-5.

3. Tae BS, Balpukov U, Cho SY, Jeong CW. Eleven-year Cumulative Incidence and Estimated Lifetime Prevalence of Urolithiasis in Korea: a National Health Insurance Service-National Sample Cohort Based Study. J Korean Med Sci. 2018;33:e13.

4. Wang S, Zhang Y, Zhang X, Tang Y, Li J. Upper urinary tract stone compositions: the role of age and gender. Int Braz J Urol. 2020;46:70-80.

5. Liu Y, Chen Y, Liao B, Luo D, Wang K, Li H, et al. Epidemiology of urolithiasis in Asia. Asian journal of urology. 2018;5:205-14.

6. Constanti M, Calvert RC, Thomas K, Dickinson A, Carlisle S. Cost analysis of ureteroscopy (URS) vs extracorporeal shockwave lithotripsy (ESWL) in the management of ureteric stones $<10 \mathrm{~mm}$ in adults: a UK perspective. BJU Int. 2020;125:457-66.

7. Ordon M, Andonian S, Blew B, Schuler T, Chew B, Pace KT. CUA Guideline: Management of ureteral calculi. Canadian Urological Association journal = Journal de l'Association des urologues du Canada. 2015; 9:E837-851.

8. Verze P, Imbimbo C, Cancelmo G, Creta M, Palmieri A, Mangiapia F, et al. Extracorporeal shockwave lithotripsy vs ureteroscopy as first-line therapy for patients with single, distal ureteric stones: a prospective randomized study. BJU Int. 2010;106:1748-52.

9. Sun XZ. Treatment of urinary residual stones. Journal of Clinical Urology. 2005; 4.

10. Chongruksut W, Lojanapiwat B, Tawichasri C, Paichitvichean S, Euathrongchit J, Ayudhya VC, et al. Kidney stones recurrence and regrowth after extracorporeal shock wave lithotripsy and percutaneous nephrolithotomy. Journal of the Medical Association of Thailand = Chotmaihet thangphaet. 2011;94:1077-83. 
11. Ermis O, Somani B, Reeves T, Guven S, Pes PL, Chawla A, et al. Definition, treatment and outcome of residual fragments in staghorn stones. Asian journal of urology. 2020;7:116-21.

12. Osman MM, Alfano Y, Kamp S, Haecker A, Alken P, Michel MS, et al. 5-year-follow-up of patients with clinically insignificant residual fragments after extracorporeal shockwave lithotripsy. European urology. 2005;47:860-4.

13. Huang WY, Chen YF, Carter S, Chang HC, Lan CF, Huang KH. Epidemiology of upper urinary tract stone disease in a Taiwanese population: a nationwide, population based study. The Journal of urology. 2013;189:2158-63.

14. Zeng G, Mai Z, Xia S, Wang Z, Zhang K, Wang L, et al. Prevalence of kidney stones in China: an ultrasonography based cross-sectional study. BJU Int. 2017;120:109-16.

15. Hrbacek J. URS versus ESWL: another contribution to the never-ending debate. Central European journal of urology. 2014;66:463-4.

16. Xu Y, Lu Y, Li J, Luo S, Liu Y, Jia Z, et al. A meta-analysis of the efficacy of ureteroscopic lithotripsy and extracorporeal shock wave lithotripsy on ureteral calculi. Acta cirurgica brasileira. 2014;29:34652.

17. Vaughan LE, Enders FT, Lieske JC, Pais VM, Rivera ME, Mehta RA, et al. Predictors of Symptomatic Kidney Stone Recurrence After the First and Subsequent Episodes. Mayo Clinic proceedings. 2019; 94:202-210.

18. Ferraro PM, Curhan GC, D'Addessi A, Gambaro G. Risk of recurrence of idiopathic calcium kidney stones: analysis of data from the literature. J Nephrol. 2017;30:227-33.

19. Gambaro G, Valente ML, Zanetti E, Della Barbera M, Del Prete D, D'Angelo A, et al. Mild tubular damage induces calcium oxalate crystalluria in a model of subtle hyperoxaluria: Evidence that a second hit is necessary for renal lithogenesis. Journal of the American Society of Nephrology: JASN. 2006;17:2213-9.

20. Miller OF, Kane CJ. Time to stone passage for observed ureteral calculi: a guide for patient education. The Journal of urology. 1999;162:688-90. discussion $690-681$.

21. Preminger GM, Tiselius HG, Assimos DG, Alken P, Buck AC, Gallucci M, et al. 2007 Guideline for the management of ureteral calculi. European urology. 2007;52:1610-31.

22. Weiss RM. Physiology of the upper urinary tract. Seminars in urology. 1987;5:148-54.

23. Matlaga BR, Jansen JP, Meckley LM, Byrne TW, Lingeman JE. Treatment of ureteral and renal stones: a systematic review and meta-analysis of randomized, controlled trials. The Journal of urology. 2012;188:130-7.

\section{Figures}



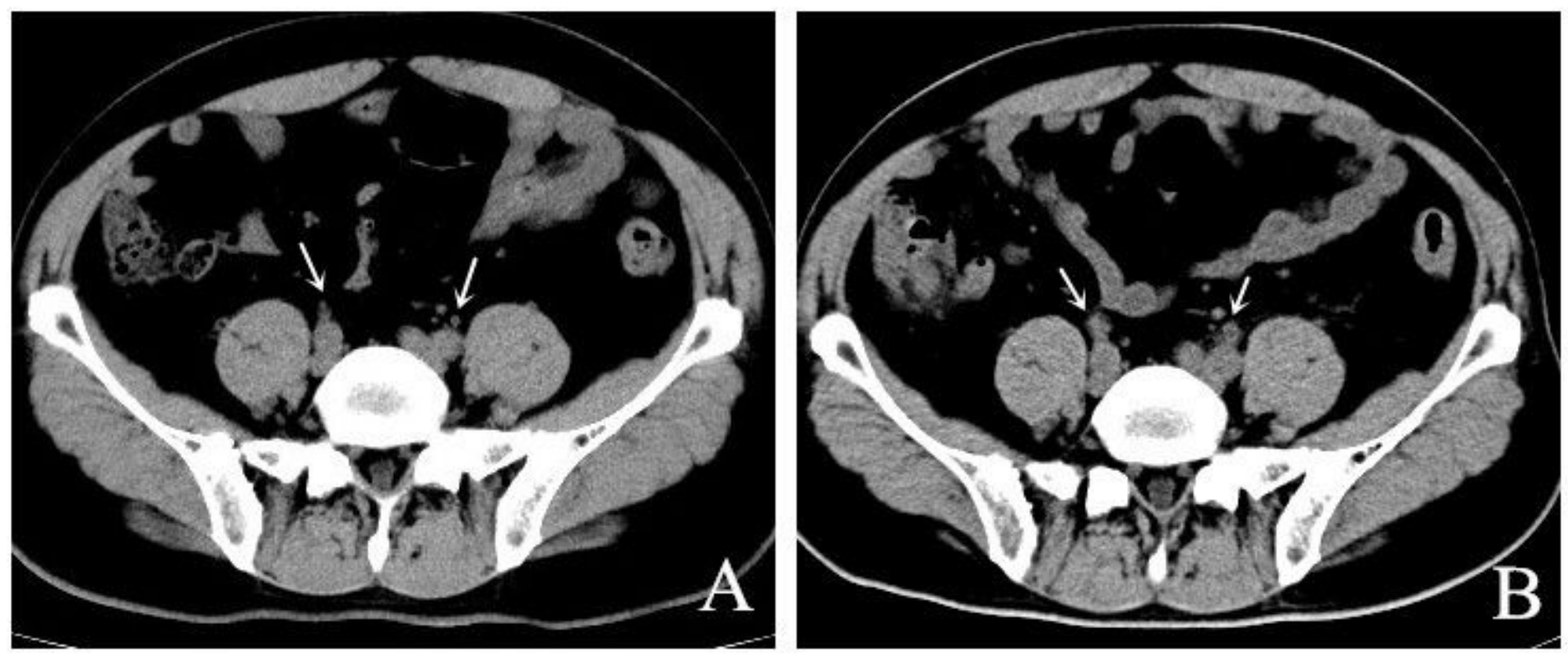

\section{Figure 1}

A 51-yr male patient complaint of right-sided lumbar pain was diagnosed with right ureteral calculus and left renal stone. He underwent ureteroscopic lithotripsy to the right ureter and left kidney. Postoperative stent replacement was given followed by a 4-week follow-up. There was no residual stones. Ultrasonography or CT scan performed 1 month later indicated bilateral ureterectasis. The ureterostenosis in the part passing through the iliac vessels at the left and right sides was $2.3 \mathrm{~mm}$, and $2.4 \mathrm{~mm}$, respectively. The post-treatment stenosis diameter at the left and right sides were $5.3 \mathrm{~mm}$ and $5.4 \mathrm{~mm}$, respectively. A: Pre-treatment findings; B: Post-treatment findings. White arrows indicated stenosis. 